\title{
Use of green fluorescent protein for detection of cell-specific gene expression and subcellular protein localization during sporulation in Bacillus subtilis
}

\author{
Peter J. Lewis and Jeffery Errington \\ Author for correspondence: Jeffery Errington. Tel: +44 1865 275561. Fax: +44 1865275556. \\ e-mail: erring@molbiol.ox.ac.uk
}

Sir William Dunn School of Pathology, University of Oxford, Oxford OX1 3RE, UK

\begin{abstract}
Wild-type and mutant forms of the gene encoding green fluorescent protein (GFP) from Aequorea victoria have been introduced into Bacillus subtilis as translational fusions to the prespore-specific and mother-cell-specific genes dacF and spolVA. In both cases, the protein was readily detected by fluorescence microscopy, and its synthesis was correctly localized. The S65T substitution, which improves the quantum yield and rate of development of fluorescence, also produced a spectral shift that allowed the protein to be colocalized with DNA, after staining with 4',6-diamidino-2-phenylindole. Three different translational fusions to the $\mathrm{N}$-terminal region of GFP all produced active protein. Moreover, a full-length SpolVA-GFP fusion showed proper targeting to the surface of the spore, albeit at low temperature and in the presence of wild-type SpolVA protein. A mutation in the gfp gene which changes the light emitted by the protein from green to blue was found not to be useful because of the intrinsic autofluorescence of $B$. subtilis in the blue part of the spectrum.
\end{abstract}

Keywords: sporulation, Bacillus subtilis, green fluorescent protein, bacterial differentiation, protein localization

\section{INTRODUCTION}

During sporulation in Bacillus subtilis, an asymmetric cell division produces a small prespore and much larger mother cell, which go on to differentiate. Differentiation is driven by the expression of distinct programmes of gene expression in the two cells. A number of methods have been used to demonstrate the cell specificity or compartmentalization of gene expression during sporulation, including physical separation of the two cells and assay of the separated fractions, analysis of the dependence of spore formation on specific genes in genetic mosaics, differential permeability of the prespore and mother cell to enzymic substrates, and immunoelectron microscopy (reviewed by Errington, 1993). Over the past few years, cytological methods based on fluorescence microscopy and either fluorogenic enzyme substrates (Bylund et al., 1994; Lewis et al., 1994a, b) or immunofluorescence (Harry et al., 1995; Pogliano et al., 1995) have been introduced.

Abbreviations: BFP, blue fluorescent protein; DAPI, 4',6-diamidino-2phenylindole; GFP, green fluorescent protein.
More recently, the green fluorescent protein (GFP) from the jellyfish Aequorea victoria has been utilized as a reporter for cell-specific gene expression in a number of systems (Chalfie et al., 1994). GFP is a small (27 kDa), intrinsically fluorescent protein. Fluorescence results from an autocatalytic cyclization between amino acids 65 and 67 to give the heterocyclic ring Ser-dehydroTyr-Gly (Cody et al., 1993). The wild-type form is excited maximally at $395 \mathrm{~nm}$ (with a minor peak at $470 \mathrm{~nm}$ ) and emits green light at $509 \mathrm{~nm}$ (Chalfie et al., 1994). GFP is known to be active in both eukaryotes and prokaryotes (Chalfie et al., 1994) and has been used to study the subcellular localization of both $\mathrm{N}$ - and $\mathrm{C}$-terminal protein fusions in Drosophila (Wang \& Hazelrigg, 1994). Useful mutations that alter the spectral properties of wild-type GFP have also been reported. One such mutation changed Tyr 66 to His $(\mathrm{Y} 66 \mathrm{H})$, resulting in a protein that emitted blue fluorescence (Heim et al., 1994). Two groups (Heim et al., 1995; Delagrave et al., 1995) reported 'red shift' mutations that showed increased quantum yields and a new maximal excitation peak at $490 \mathrm{~nm}$. The S65T mutant reported by Heim et al. (1995) also forms the heterocyclic fluorescent tripeptide more rapidly than the wild-type 
protein, with half maximal fluorescence developing in 20 min versus $2 \mathrm{~h}$, due to the elimination of a dehydration step. Compared with other methods of cytological detection of gene expression, GFP has the advantages that fixation and exogenous addition of substrates are not required (although it requires an aerobic environment). Thus, real-time analysis of cell-specific gene expression is possible in live samples, as has been reported for Drosophila (S. Kain, personal communication).

Here we demonstrate that GFP can be fused to sporulation genes and used to detect compartmentalized gene expression in B. subtilis. The S65T variant of GFP can be visualized in cells that have been counter-stained with the DNA specific dye 4',6-diamidino-2-phenylindole (DAPI). Synthesis of the reporter protein can then be related to the stage of morphological development in each cell. A fusion to full-length SpoIVA protein was initially found not to exhibit the expected assembly into the spore coat (Driks $e t$ al., 1994). However, by reducing the incubation temperature and complementing with a wild-type copy of the spoIVA gene, we were able to detect normal-looking assembly, suggesting that fusions to GFP may be useful for studying the subcellular targeting of proteins in this organism. While this work was in progress, we learned that similar results were being obtained in another laboratory (Arigoni et al., 1995; Webb et al., 1995).

\section{METHODS}

Bacterial strains. The Escherichia coli strain used for all cloning was $\mathrm{DH} 5 \alpha, \mathrm{F}^{-}$end $A 1$ bsd $\mathrm{R} 17\left(\mathrm{r}_{\mathrm{K}}^{-} \mathrm{m}_{\mathrm{K}}^{-}\right) \operatorname{supE} 44$ thi-1 $\lambda^{-} \operatorname{rec} A 1$ gyr $A 96$ relA1 $\Delta($ lacZY $A$-argF) U169 $\phi 80 \mathrm{~d} l a c Z \Delta M 15$ (GibcoBRL). Bacillus subtilis strains used are listed in Table 1. Strains containing integrated plasmids were constructed by transforming strain SG38 with plasmid DNA and plating on nutrient agar containing chloramphenicol $\left(5 \mu \mathrm{g} \mathrm{ml}^{-1}\right)$. Strain 1026 was constructed by transforming strain 1025 with chromosomal DNA from strain 901 (Wu et al., 1995), and selecting on nutrient agar plates containing chloramphenicol and kanamycin $\left(5 \mu \mathrm{g} \mathrm{ml}^{-1}\right.$ each). The spoIV $A$ defect in strain 1022 was complemented by lysogeny with phage $\phi 105 \mathrm{~J} 108\left(\right.$ spoIV $\left.A^{+}\right)$ (East \& Errington, 1989) as described by Errington (1990).

Construction of plasmids. The plasmids used are also listed in Table 1. All recombinant plasmids were checked by PCR cycle sequencing using the protocol described by ABI. Oligonucleotides were synthesized ( $40 \mathrm{nmol}$ scale) using an ABI 394 DNA synthesizer and diluted as required for PCR and sequencing.

pSG1125, a vector for generation of translational fusions to GFP, was constructed as follows. Wild-type $g f p$ was obtained from plasmid TU\#58 (M. Chalfie, Columbia University, NY, USA) by PCR using the oligonucleotides: $5^{\prime}$-T'T'TCTGCAGATGAGTAAAGGAGAAGAAC'T'T- $3^{\prime}$ and $5^{\prime}$-CGGACAC'T'TTAGTGTAGATCTGAAGTCTGGAC-3'. The purified product was digested with $P_{s t} \mathrm{I}$ and $B g / \mathrm{II}$ and inserted into Pst / BamHI-digested pSG1301 (Stevens et al., 1992). pSG1137

Table 1. B. subtilis strains and plasmids used in this work

\begin{tabular}{|c|c|c|}
\hline $\begin{array}{l}\text { Strain/ } \\
\text { plasmid }\end{array}$ & Genotype & Construction, source or reference \\
\hline \multicolumn{3}{|l|}{ B. subtilis } \\
\hline SG38 & $\operatorname{trpC2}$ amyE & Errington \& Mandelstam (1986) \\
\hline 901 & $\operatorname{trp} C 2 \Omega(\operatorname{spoIIG} A:: a p b-A 3) 901$ & Wu et al. (1995) \\
\hline 1022 & spoIV $A::$ pSG1141 (spoIV $A^{\prime}-g f p S 65$ Tcat $) \operatorname{trp} C 2$ amyE & This work \\
\hline 1024 & spoIV $A$ ::pSG1145 (spoIV $A^{291}-g f p S 65 T$ cat) trpC2 amyE & This work \\
\hline 1025 & dacF::pSG1147 (dacF'-gfpS65T cat) trpC2 amyE & This work \\
\hline 1026 & $\begin{array}{l}\text { dacF ::pSG1147 (dacF'-gfpS65T cat) } \Omega(\text { spoIIG } A:: a p h- \\
\text { A3)901 trpC2 amyE }\end{array}$ & This work \\
\hline \multicolumn{3}{|l|}{ Plasmids } \\
\hline TU\#58 & bla gfp & Chalfie et al. (1994) \\
\hline pMS100 & bla cat dac $F^{\prime}-$ lac $Z$ & M. E. Sharpe (unpublished) \\
\hline pSG1125 & bla cat gfp & Cloning vector for C-terminal translational fusions to GFP \\
\hline pSG1135 & bla cat bfp & Cloning vector for $\mathrm{C}$-terminal translational fusions to BFP \\
\hline pSG1137 & bla cat gfp $S 65 T$ & $\begin{array}{l}\text { Cloning vector for C-terminal translational fusions to } \\
\text { GFP65T }\end{array}$ \\
\hline pSG1141 & bla cat gfpS65T spoIVA (723-1782)* & $\begin{array}{l}1059 \text { bp HindIII-PstI fragment of PCR-amplified spoIV A } \\
\text { DNA cloned into HindIII/PstI-digested pSG1137 }\end{array}$ \\
\hline pSG1145 & bla cat gfpS65T spoIVA (723-1191) & $\begin{array}{l}468 \text { bp HindIII-EcoRI fragment of PCR-amplified spoIVA } \\
\text { DNA cloned in-frame into HindIII/EcoRI-digested } \\
\text { pSG1137 }\end{array}$ \\
\hline pSG1147 & bla cat gfpS65T dacF (312-601)† & $\begin{array}{l}289 \text { bp HindIII-XbaI (filled) fragment of pMS100 cloned } \\
\text { into HindIII/PstI-digested pSG1137 (blunted) }\end{array}$ \\
\hline pSG1301 & bla cat & Stevens et al. (1992) \\
\hline
\end{tabular}

* Numbers in parentheses relate to the sequence numbers given in Stevens et al. (1992).

† Numbers in parentheses relate to the sequence numbers given in Wu et al. (1992). 


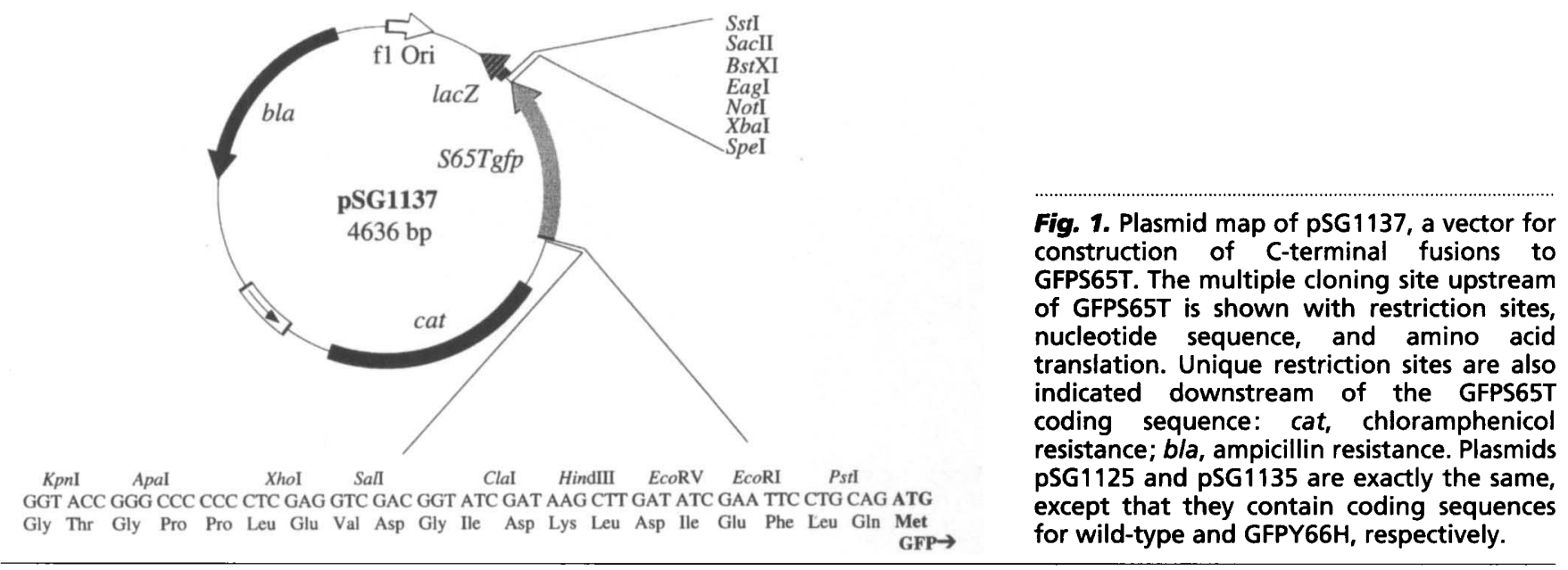

Table 2. Cellular location of GFP during sporulation

\begin{tabular}{|c|c|c|c|c|c|c|c|}
\hline \multirow[t]{2}{*}{ Strain } & \multirow[t]{2}{*}{ Time (no. cells) } & \multicolumn{3}{|c|}{ Location of fluorescence (no. cells) } & \multicolumn{3}{|c|}{ Cells at morphological stage (\%) } \\
\hline & & Prespore & Mother cell & Whole cell & II & III & IV \\
\hline \multirow[t]{2}{*}{1022} & $t_{4}(198)$ & 0 & 77 & 0 & 12 & $88^{*}$ & \\
\hline & $t_{5}(176)$ & 0 & 84 & 0 & 7 & $93 *$ & \\
\hline \multirow[t]{3}{*}{1025} & $t_{3}(451)$ & 293 & 0 & 1 & 58 & 34 & 8 \\
\hline & $t_{4}(124)$ & 110 & 0 & 0 & 17 & 44 & 39 \\
\hline & & & & & One 'prespore' & Two & ores' \\
\hline \multirow[t]{2}{*}{$1026+$} & $t_{3}(441)$ & 238 & 0 & 0 & 48 & & \\
\hline & $t_{4}(118)$ & 65 & 0 & 0 & 37 & & \\
\hline
\end{tabular}

* Since phase-bright spores are not produced in spoIV $A$ mutants, these ceils are scored as being stage $\geqslant$ III.

† Since strain 1026 is an abortive disporic mutant, cells were scored as having either one or two fluorescent prespore-like cells.

(Fig. 1) was obtained by in vitro mutagenesis (Sambrook et al., 1989) using the oligonucleotide $5^{\prime}$-ACTACTTTCACTTATGGTGT'T-3', which changes amino acid 65 of $g f p$ from Ser to Thr to give GFPS65T (Heim et al., 1995). pSG1135 was also made by in vitro mutagenesis using the oligonucleotide $5^{\prime}$-ACTACTTTCACTCATGGTGTT-3', which changes amino acids 65 and 66 of GFP to Thr and His, respectively. Mutants were obtained with changes solely at position 66 (His) and at positions 65 and 66. Heim et al. (1994) reported that changing amino acid 66 from Tyr to His produced a blue fluorescent protein (BFP) with a major absorbance peak at $382 \mathrm{~nm}$ and emission at $448 \mathrm{~nm}$. The rationale in also incorporating the S65T muation was that a brighter more rapidly forming BFP might be produced. It has subsequently been reported that such an effect is not observed (S. Kain, personal communication), so only the $\mathrm{Y} 66 \mathrm{H}$ single mutant was used in experiments reported below.

A $\operatorname{dac} F^{\prime}-' S 65 T g f p$ translational fusion was constructed as follows. Plasmid pMS100 (M. E. Sharpe, personal communication), containing a $289 \mathrm{bp}$ fragment of $\operatorname{dac} F$ including the promoter, was digested with $\mathrm{XbaI}$, end-filled with the Klenow fragment of DNA polymerase, then digested with HindIII. The promoter fragment was purified and ligated to pSG1137 that had been digested with PstI, blunted with Klenow, and digested with HindIII. This gave plasmid pSG1147, in which the first 33 codons of $d a c F$ were fused in-frame with $g f p S 65 T$. A dacF $F^{\prime}-b f p$ fusion, in plasmid pSG1146 was produced in the same way, except PSG1135 was the vector plasmid.

Fusions of spoIVA to gfpS65T were constructed as follows. spoIV $A$ was amplified from chromosomal DNA of strain SG38 using the following oligonucleotides: $5^{\prime}$-ATCGGCACACGAAAGCT'TATTCAAGAACAC-3', corresponding to nucleotides (nt) 709-738 of the sequence of Stevens et al. (1992), and 5'AGAGGTCTACCGGTACTGCAGGATGATGGC-3', corresponding to nt 1800-1771 of the sequence of Stevens et al. (1992). Amplification with these oligonucleotides inserted a unique HindIII site at nt 723 and a unique PstI site at nt 1782. To construct plasmid pSG1141, the HindIII-PstI fragment was inserted into HindIII/PstI-digested pSG1137. This produced an in-frame fusion of the promoter-distal part of spoIV $A$ to the complete coding sequence of $g f p S 65 T$ (Table 1 ). The fusion junction between $s p o I V A$ and $g f p S 65 T$ was such that no additional amino acids would be introduced between the final amino acid of SpoIVA and the first of GFPS65T.

To fuse $g f p S 65 T$ to a truncated spoIV $A$ gene, the 1059 bp PCR product described above was digested with EcoRI and HindIII, and ligated to EcoRI/HindIII-digested pSG1137. The resulting plasmid, pSG1145, contained a 468 bp insertion encoding amino acids 135-291 of SpoIVA fused in-frame with the gfpS65T gene via a $12 \mathrm{bp}$ bridge. After transformation of $B$. subtilis this construction would lead to the synthesis of a fusion protein with 


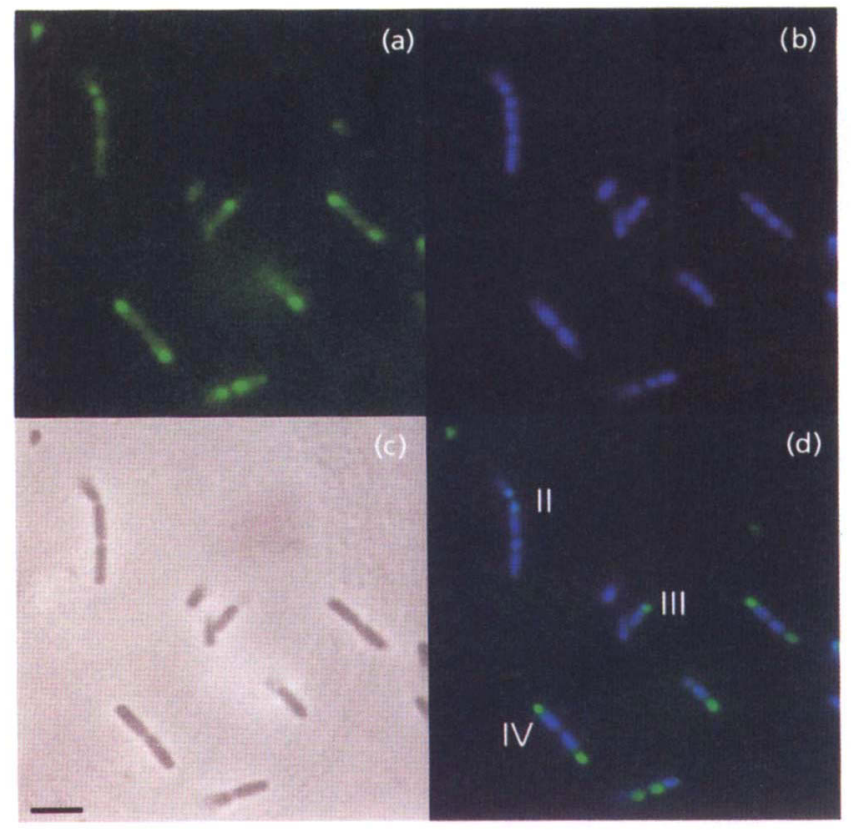

Fig. 2. Compartment-specific expression of a dacF'-gfpS65T fusion in strain 1025 at $t_{4}$. (a) GFPS65T fluorescence; (b) DAPI fluorescence; (c) phase-contrast image; (d) images of (a) and (b) merged, showing co-localization of GFPS65T fluorescence and the DAPI-stained prespore nucleoid. Cells at stages II, III and IV of sporulation are indicated. Bar, $4 \mu \mathrm{m}$.

the following sequence: SpoIVA ${ }^{1-291}$-Glu-Phe-Leu-GlnGFPS65T.

spoIV $A$ fusions with the wild-type $g f p$ gene were constructed in the same way, except that the vector plasmid was pSG1125.

Transformation of $\boldsymbol{B}$. subtilis. Transformations were done by standard laboratory techniques (Anagnostopoulos \& Spizizen, 1961; Jenkinson, 1983).

Induction of sporulation. Cells were grown and induced to sporulate by the resuspension method of Sterlini \& Mandelstam (1969) as specified by Partridge \& Errington (1993). Sporulation medium was supplemented with $2 \mu \mathrm{g}$ chloramphenicol $\mathrm{ml}^{-1}$.

Visualization of fluorescence. At appropriate times, $200 \mu \mathrm{l}$ samples of cells were taken, pelleted by centrifugation, and resuspended in $200 \mu \mathrm{l}$ sterile water. A $3 \mu \mathrm{l}$ aliquot of cell suspension was then mixed with $1 \mu$ DAPI $\left(1 \mu \mathrm{g} \mathrm{ml}^{-1}\right.$; Sigma) on a slide pre-coated with $0.01 \%$ polylysine (Sigma). A coverslip, also pre-coated with polylysine, was then placed on top. Cells were viewed by epifluorescence microscopy using a Zeiss Axiovert $135 \mathrm{TV}$ epifluorescence microscope with a $100 \mathrm{~W}$ mercury lamp source, a $\times 100$ Plan-Neofluar oil-immersion objective lens (numerical aperture 1.3), and a $\times 2.5$ optovar in place. A SYS $2000800 \times 1200$ pixel cooled CCD camera (Digital Pixel Advanced Imaging Systems) was attached to the microscope camera port and images were captured with Lucida V 2.x software (Kinetic Imaging).

GFP fluorescence was viewed with $\mathrm{HQ}$ : fluorescein isothiocyanate (FITC) filter set 41001 (Chroma Technology) (excitation wavelength $450-505 \mathrm{~nm}$; long pass $505 \mathrm{~nm}$; emission $510-560 \mathrm{~nm}$ ). The exposure time was $3 \mathrm{~s}$ for all GFP images, except for those of Fig. 5, which were for $10 \mathrm{~s}$. Phase contrast images ( $300 \mathrm{~ms}$ exposure) were then obtained with the HQ: FITC filter set still in place. Finally, $100 \mathrm{~ms}$ DAPI images

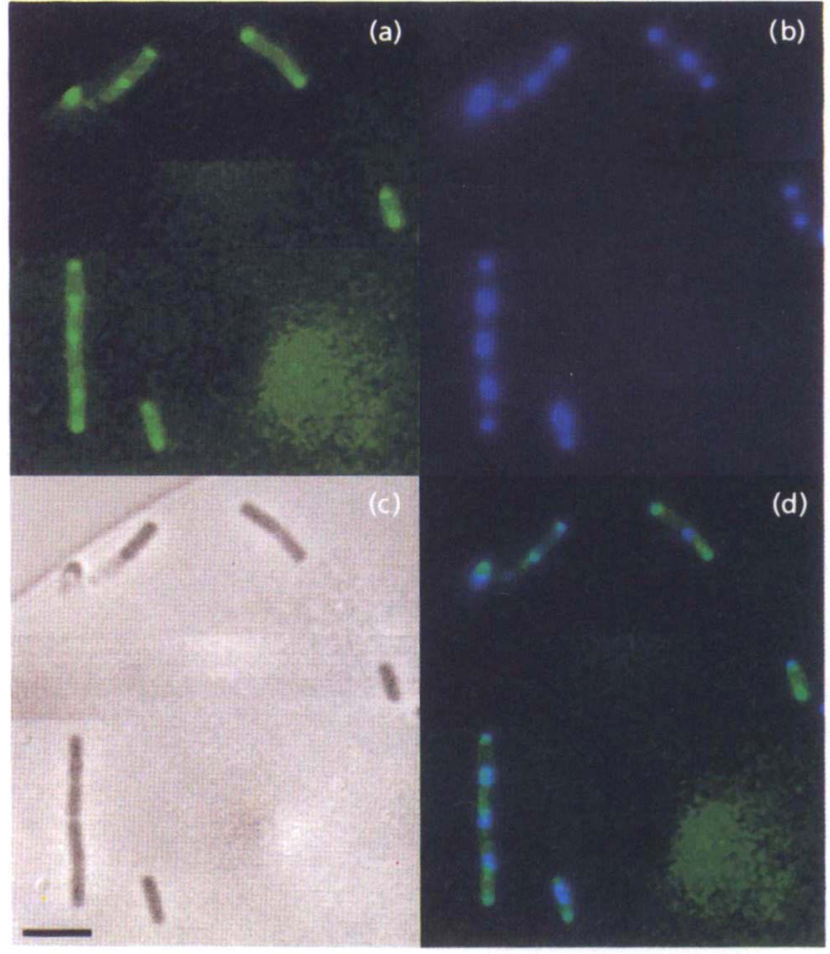

Fig. 3. Compartment-specific expression of a dacF'-gfpS65T fusion in a spol/G (abortive disporic) mutant strain 1026 at $t_{3}$. Parts (a-d) and scale bar as in Fig. 2. Due to the low density of cells in the field, the image was cropped to exclude some blank spaces.

were obtained with the narrow band set for DAPI (filter set 31013, Chroma; excitation wavelength 355-375 nm; LP $400 \mathrm{~nm}$; emission $435-490 \mathrm{~nm}$ ). Separate background images were obtained for GFP, phase contrast and DAPI images, and these were subtracted from raw images during processing. Image overlays and micrograph figures were prepared with Adobe Photoshop version 3.0.4.

\section{RESULTS}

\section{Vectors for construction of fusions to GFP}

The coding sequence of $g f p$ was amplified by PCR as described in Methods and cloned into plasmid pSG1301 to generate a convenient vector with which to make fusions that could be readily introduced into $B$. subtilis. The resultant plasmid, pSG1125, contains the following useful functions: an origin of replication that functions in $E$. coli but not in $B$. subtilis; antibiotic resistance determinants, bla for selection in E. coli and cat for B. subtilis; and multiple cloning sites for generating C-terminal fusions to the $g f p$ gene. The plasmid [which was based originally on pBluescript $\mathrm{KS}(-)$; Stratagene] also contains the phage $f 1$ origin for generation of single-stranded DNA, which facilitates the construction of new $g f p$ derivatives by site-directed mutagenesis. Two mutant forms of $g f p$ were constructed in the course of this work. The S65T substitution was introduced into pSG1125 to generate plasmid pSG1137 (Fig. 1), which was used as the 


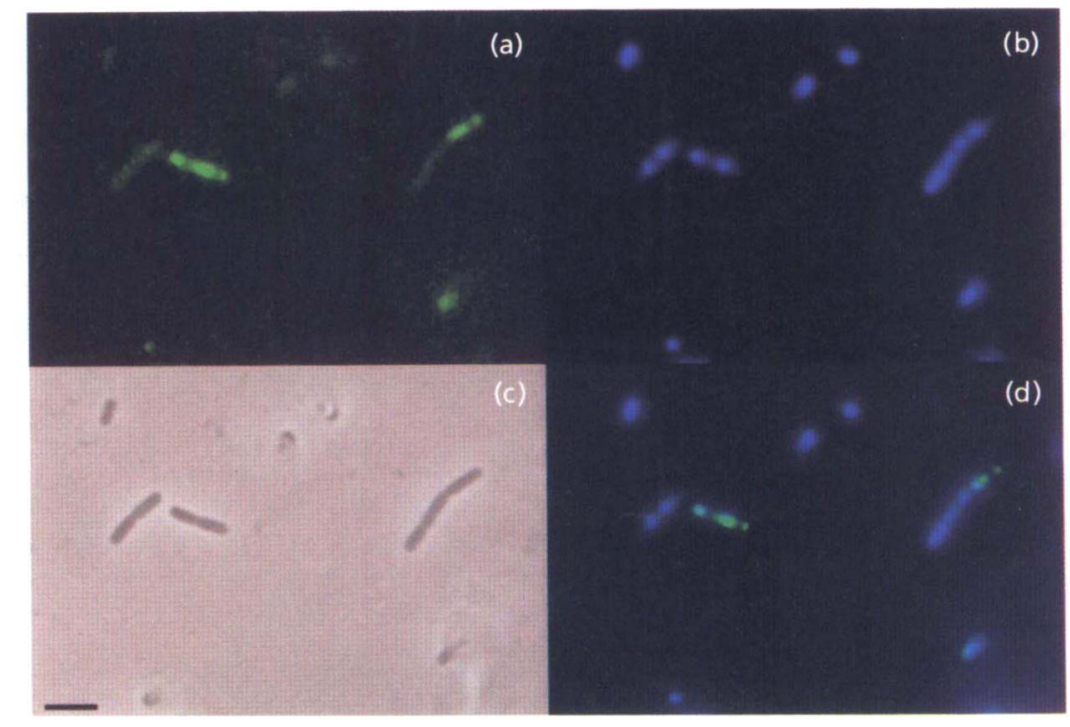

Fig. 4. Compartment-specific expression of a spolvA'-gfpS65T fusion in strain 1022 at $t_{4}$. Parts (a-d) and scale bar as in Fig. 2.

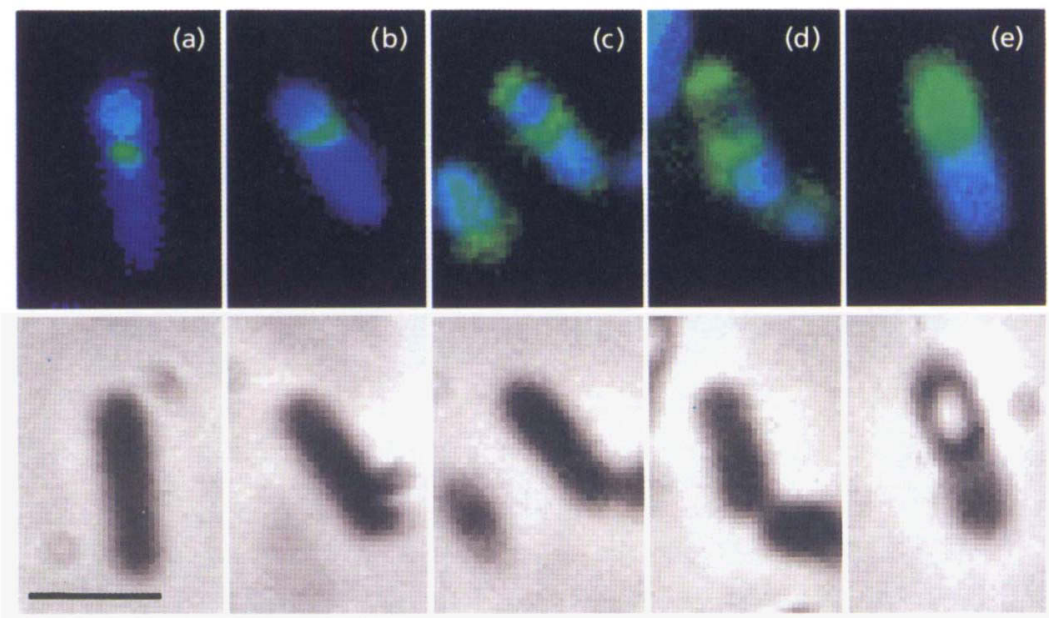

Fig. 5. Subcellular assembly of SpolvAGFPS65T around the developing prespore in strain 1022 lysogenic for phage $\phi 105 J 108$ $\left(\right.$ spolvA $\left.{ }^{+}\right)$. The culture was induced to sporulate by resuspension at $25^{\circ} \mathrm{C}$ and samples were taken at $t_{13}(\mathrm{a}-\mathrm{c})$ and $t_{18}(\mathrm{~d}, \mathrm{e})$. The upper panels show merged GFP (green) and DAPI (blue) images. The lower panels show corresponding phase-contrast images. Bar, $2 \mu \mathrm{m}$.

vector for the construction of the various fusions described below. This substitution was reported to have several beneficial effects as discussed above (Heim et al., 1995). The shift in the peak emission wavelength was particularly useful because it allowed co-localization of the mutant protein and DNA (stained with DAPI).

Several of the plasmids described below were also modified to carry the $\mathrm{Y} 66 \mathrm{H}$ substitution. This change was reported to alter the spectral properties of GFP so that it emits blue light rather than green (Heim et al., 1994). However, use of this protein in $B$. subtilis turned out to be impractical, because of cell autofluorescence at the emission peak of this modified protein (results not shown).

\section{GFP as a marker for prespore-specific gene expression}

A 289 bp fragment of DNA containing the promoter and first 33 codons of the prespore-specific ( $\sigma^{\mathrm{F}}$-dependent) dacF gene (Schuch \& Piggot, 1994) was cloned into plasmid pSG1137 to generate an in-frame fusion to gfpS65T (see Methods). The resultant plasmid, pSG1147, was transformed into $\mathrm{Spo}^{+}$B. subtilis strain SG38, with selection for chloramphenicol resistance. Cells transformed with this type of plasmid arise by single crossover homologous recombination (Duncan et al., 1978). A transformant, designated strain 1025, was induced to sporulate by the resuspension method (Sterlini \& Mandelstam, 1969) and at intervals the cells were viewed by fluorescence microscopy (Fig. 2). Fluorescence in the emission range expected for GFPS65T began to be detected at about $t_{2}$ ( $2 \mathrm{~h}$ after the initiation of sporulation), which is similar to the time of expression of a $\operatorname{dacF}-\mathrm{lac} Z$ fusion reported by Schuch \& Piggot (1994). The proportion of fluorescent cells increased to $61 \%$ at $t_{3}$, and by $t_{4}$ virtually all of the prespores $(89 \%$ ) fluoresced (Table 2 ).

The appearance of the areas of fluorescence, small, roughly spherical and situated close to the cell pole, was consistent with the GFP being specifically synthesized in the prespore compartment (Lewis et al., 1994a, b). Because there was no detectable spectral crossover between the 
fluorescence emitted by GFPS65T and the DNA-specific fluorescent dye DAPI (results not shown), it was possible to counterstain cells to view their chromosomes. Superimposition of the two fluorescent images (Fig. 2d) confirmed that the GFP fluorescence always co-localized with the prespore nucleoid. The DAPI staining also allowed three different morphological classes of cells exhibiting GFP fluorescence to be distinguished (Fig. 2d). At stage II, the prespore DNA is tightly compacted into the small prespore compartment and its maximum fluorescence is considerably greater than that of the mother cell. At stage III, when prespore engulfment is complete, the prespore DNA occupies a larger space and consequently has a reduced maximum fluorescence. Later in development, at about stage IV, the prespore DNA becomes refractory to staining by DAPI (Setlow et al., 1991). As expected, at $t_{4}$, the fluorescent prespores tended to have reached a later stage of development than at $t_{3}$ (Table 2). In general, the level of GFP fluorescence also increased in accordance with the morphological progression (Fig. 2).

To confirm the prespore localization of $d a c F-g f p S 65 T$ and demonstrate its effectiveness as a cytological marker, a spoIIG mutation was introduced into strain 1025 to give strain 1026. spoIIG mutations eliminate the mother-cellspecific sigma factor $\sigma^{\mathrm{E}}$ and lead to a 'disporic' phenotype, in which prespore-like cells are formed at both poles of the sporulating cell, leaving a central anucleate compartment. As shown in Fig. 3, GFP fluorescence was readily detected at either one or both poles of the sporulating cells of strain 1026. A slightly lower proportion of the cells exhibited fluorescence than with strain 1025, probably because dac $F$ is transcribed by RNA polymerase containing either $\sigma^{\mathrm{F}}$ or the later presporespecific sigma factor $\sigma^{G}$ (Schuch \& Piggot, 1994), and the spoIIG mutation eliminates the contribution made by $\sigma^{\mathrm{G}}$ (Partridge \& Errington, 1993). The detection of cells in which only one prespore was fluorescing, especially in the earlier $t_{3}$ sample, was consistent with previous experiments showing that the prespore-like cells of these mutants form sequentially (Lewis et al., 1994b).

\section{GFP as a marker for mother-cell-specific gene expression}

To test whether GFP could be used to study mother-cellspecific gene expression, a fusion to the spoIV $A$ gene was constructed, again using pSG1137 and the GFPS65T mutant gene. Plasmid pSG1141 was transformed into SG38, again generating the fusion by single crossover homologous recombination (strain 1022). In this case, the whole of the spoIV $A$ coding sequence was fused in-frame with $g f p$ (see Table 1). Unexpectedly, the resultant transformants were $\mathrm{Spo}^{-}$, suggesting that the fusion protein is non-functional (see below). The pattern of fluorescence exhibited by the $s p o I V A-g f p$ fusion was quite different from that of $d a c F-g f p$. Fluorescence was restricted to the mother cell compartment, as revealed by the DAPI staining (Fig. 4; Table 2). Cells at different stages of sporulation showed a pattern of GFP fluorescence consistent with the protein occupying the whole of the mother cell cytoplasm; at stage II, a single cylindrical region of staining to one side of the prespore DNA was visible, whereas at stage III (visible in Fig. 4), fluorescence was additionally detectable in the mother cell cytoplasm at the distal side of the engulfed prespore. In this experiment, no attempt was made to distinguish between cells at stages III and IV, because the loss of DAPI staining which occurred in wild-type sporulating cells at stage IV was less obvious in the spoIV $A$ mutant cells.

Similar results were obtained with strain 1024, in which $g f p$ was fused to the $\mathrm{N}$-terminal coding half of the spoIV $A$ gene rather than to the whole gene (results not shown).

\section{Subcellular localization of SpoIVA-GFP}

Although the above results confirmed the cell specificity of synthesis of the SpoIVA-GFP fusion proteins, it appeared that the full-length fusion protein in strain 1022 was not, like native SpoIVA, targeted to the assembling spore coat (Driks et al., 1994). The fact that the cells with this fusion became $\mathrm{Spo}^{-}$, despite having the whole of the SpoIVA-coding sequence, indicated that addition of GFP to the C-terminal tail of SpoIVA interferes with the function of the latter. However, discrete localization of the hybrid fluorescent protein was obtained by use of two adjustments to the method. First, the experiments were done at lower temperatures $\left(20-22^{\circ} \mathrm{C}\right)$. This resulted in detection of discrete regions of higher fluorescence generally located between the prespore and the mother cell nucleoids (data not shown). Second, a wild-type copy of the spoIVA gene was introduced into strain 1022. In this case, a culture resuspended at low temperature gave rise to cells in which the expected pattern of assembly of the hybrid SpoIVA-GFPS65T protein around the prespore was readily detected (Fig. 5). The cells shown in $(\mathrm{a}-\mathrm{c})$ were obtained at $t_{13}$ and those in (d) and (e) at $t_{18}$. They represent cells apparently having reached stages IIii, IIiii, III, IV and V, respectively (Errington, 1993). At stage IIii (Fig. 5a), the prespore septum is largely intact, and SpoIVA-GFPS65T has assembled in the middle of the septum at the site where septal hydrolysis is first observed (Driks et al., 1994). During stage IIiii (Fig. 5b), septal hydrolysis is completed and the initial stages of prespore engulfment have been initiated. The SpoIVAGFPS65T fusion can be seen assembled on the surface of the outer prespore membrane. By stage III (Fig. 5c), the prespore has been fully engulfed and the SpoIVAGFPS65T fusion appears to completely surround the prespore. At stage IV (Fig. 5d), the prespore becomes refractory to DAPI staining, which occurs at about the time that cortex formation is initiated. At stage V (Fig. $5 e)$, the developing spore has become phase bright. The region of fluorescence now completely surrounds the developing spore. At later stages of development, GFP fluorescence disappeared, which may indicate that the fusion protein becomes buried by the outer layers of the coat. 


\section{DISCUSSION}

We have demonstrated that GFP has considerable potential for use as a cytological marker for gene expression during sporulation in B. subtilis. Presumably, it may find many other applications in situations in which cell-to-cell heterogeneity of gene expression is liable to occur.

Fusions to prespore-specific and mother-cell-specific genes both gave the expected patterns of expression. In combination with DAPI staining, we were able to distinguish several distinct morphological stages of sporulation in unfixed cells. Such fusions should be of use in a number of future studies, e.g. in identifying and characterizing mutants with altered morphology, or in studying the fate of sporulating cells after reversal of starvation ( $G$. Parker \& J. Errington, unpublished). Although our preliminary experiments with BFP proved to be unfruitful, it is likely that other colour variants of GFP, or different fluorogenic proteins, will become available, and these will open up the possibility of double labelling, colocalization experiments.

Protein fusions to GFP are beginning to be used extensively to study subcellular protein localization in eukaryotic systems. In the preliminary experiments reported here, we have been able to detect targeting of a SpoIVA-GFP fusion protein to the surface of the prespore, where SpoIVA is known to participate in the assembly of the spore coat (Driks et al., 1994). The Spophenotype of the strain with the fusion of the full-length SpoIVA and GFP proteins may be due to impaired folding of the SpoIVA moiety. Perhaps at lower temperature folding is more efficient and a degree of targeting to the surface of the spore is revealed. Irrespective of whether this explanation is correct, introduction of wildtype SpoIVA protein by complementation with phage $\phi 105 \mathrm{~J} 108$ appeared to allow correct assembly of the fusion protein into the spore coat. It is possible that modifications such as production of an $\mathrm{N}$-terminal fusion to GFP, or introduction of a short 'linker region' between the two protein domains, might facilitate folding and allow proper targeting to occur at higher temperatures and/or in the absence of wild-type protein. It seems likely that further application of methods based on fusions to GFP will bring about major advances in our understanding of the subcellular organization of bacterial cells.

\section{ACKNOWLEDGEMENTS}

This work was supported by the Biotechnology and Biological Sciences Research Council. We thank R. Losick for communicating results in advance of publication.

\section{REFERENCES}

Anagnostopoulos, C. \& Spizizen, J. (1961). Requirements for transformation in Bacillus subtilis. J Bacteriol 81, 741-746.

Arigoni, F., Pogliano, K., Webb, C. D., Stragier, P. \& Losick, R. (1995). Localization of protein implicated in establishment of cell type to sites of asymmetric division. Science 270, 637-640.

Bylund, J. E., Zhang, L., Haines, M. A., Higgins, M. L. \& Piggot, P. J. (1994). Analysis by fluorescence microscopy of the development of compartment-specific gene expression during sporulation of Bacillus subtilis. J Bacteriol 176, 2898-2905.

Chalfie, M., Tu, Y., Euskirchen, G., Ward, W. W. \& Prasher, D. C. (1994). Green fluorescent protein as a marker for gene expression. Science 263, 802-805.

Cody, C. W., Prasher, D. C., Westler, W. M., Pendergast, F. G. \& Ward, W. W. (1993). Chemical structure of the hexapeptide chromophore of the Aequorea green-fluorescent protein. Biochemistry 32, 1212-1218.

Delagrave, S., Hawtin, R. E., Silva, C. M., Yang, M. M. \& Youvan, D. C. (1995). Red-shifted excitation mutants of the green fluorescent protein. Bio/Tecbnology 13, 151-154.

Driks, A., Roels, S., Beall, B., Moran, C. P., Jr \& Losick, R. (1994). Subcellular localization of proteins involved in the assembly of the spore coat of Bacillus subtilis. Genes \& Dev 8, 234-244.

Duncan, C. H., Wilson, G. A. \& Young, F. E. (1978). Mechanism of integrating foreign DNA during transformation of Bacillus subtilis. Proc Natl Acad Sci US A 75, 3664-3668.

East, A. K. \& Errington, J. (1989). A new bacteriophage vector for cloning in Bacillus subtilis and the use of $\phi 105$ for protein synthesis in maxicells. Gene 81, 35-43.

Errington, J. (1990). Gene cloning techniques. In Molecular Biological Methods for Bacillus, pp. 175-220. Edited by C. R. Harwood \& S. M. Cutting. Chichester: Wiley.

Errington, J. (1993). Bacillus subtilis sporulation: regulation of gene expression and control of morphogenesis. Microbiol Rev 57, 1-33.

Errington, J. \& Mandelstam, J. (1986). Use of a lac $Z$ gene fusion to determine the dependence pattern of sporulation operon spoII $A$ in spo mutants of Bacillus subtilis. J Gen Microbiol 132, 2967-2976.

Harry, E. J., Pogliano, K. \& Losick, R. (1995). Use of immunofluorescence to visualize cell-specific gene expression during sporulation in Bacillus subtilis. J Bacteriol 177, 3386-3393.

Heim, R., Prasher, D. C. \& Tsien, R. Y. (1994). Wavelength mutations and posttranslational autoxidation of green fluorescent protein. Proc Natl Acad Sci USA 91, 12501-12504.

Heim, R., Cubitt, A. B. \& Tsien, R. Y. (1995). Improved green fluorescence. Nature 373, 663-664.

Jenkinson, H. F. (1983). Altered arrangement of proteins in the spore coat of a germination mutant of Basillus subtilis. J Gen Microbiol 129, 1945-1958.

Lewis, P. J., Nwoguh, C. E., Barer, M. R., Harwood, C. R. \& Errington, J. (1994a). Use of digitized video microscopy with a fluorogenic enzyme substrate to demonstrate cell- and compartment-specific gene expression in Salmonella enteritidis and Bacillus subtilis. Mol Microbiol 13, 655-662.

Lewis, P. J., Partridge, S. R. \& Errington, J. (1994b). $\sigma$ factors, asymmetry, and the determination of cell fate in Bacillus subtilis. Proc Natl Acad Sci US A 91, 3849-3853.

Partridge, S. R. \& Errington, J. (1993). The importance of morphological events and intercellular interactions in the regulation of prespore-specific gene expression during sporulation in Bacillus subtilis. Mol Microbiol 8, 945-955.

Pogliano, K., Harry, E. J. \& Losick, R. (1995). Visualization of the subcellular location of sporulation proteins in Bacillus subtilis using immunofluorescence microscopy. Mol Microbiol 18, 459-470.

Sambrook, J., Fritsch, E. F. \& Maniatis, T. (1989). Molecular Cloning: a Laboratory Manual. Cold Spring Harbor, NY: Cold Spring Harbor Laboratory.

Schuch, J. \& Piggot, P. J. (1994). The dacF-spoII $A$ operon of Bacillus subtilis, encoding sigma $\mathrm{F}$, is autoregulated. $J$ Bacteriol 176, $4104-4110$. 
Setlow, B., Magill, N., Febbroriello, P., Nakhimovsky, L., Koppel, D. E. \& Setlow, P. (1991). Condensation of the forespore nucleoid early in sporulation of Bacillus species. J Bacteriol 173, 6270-6278.

Sterlini, J. M. \& Mandelstam, J. (1969). Commitment to sporulation in Bacillus subtilis and its relationship to the development of actinomycin resistance. Biochem $J$ 113, 29-37.

Stevens, C. M., Daniel, R., Illing, N. \& Errington, J. (1992). Characterization of a sporulation gene, spoI $V A$, involved in spore coat morphogenesis in Bacillus subtilis. J Bacteriol 174, 586-594.

Wang, S. \& Hazelrigg, T. (1994). Implications for bcd mRNA localization from spatial distribution of exu protein in Drosophila oogenesis. Nature 369, 400-403.

Webb, C. D., Decatur, A., Teleman, A. \& Losick, R. (1995). Use of green fluorescent protein for visualization of cell-specific gene expression and subcellular protein localization during sporulation in Bacillus subtilis. J Bacteriol 177, 5906-5911.

Wu, J.-J., Schuch, R. \& Piggot, P. J. (1992). Characterization of a Bacillus subtilis sporulation operon that includes genes for an RNA polymerase $\sigma$ factor and for a putative DD-carboxypeptidase. $J$ Bacteriol 174, 4885-4892.

Wu, L. J., Lewis, P. J., Allmansberger, R., Hauser, P. M. \& Errington, J. (1995). A conjugation-like mechanism for prespore chromosome partitioning during sporulation in Bacillus subtilis. Genes \& Dev 9, 1316-1326.

Received 16 October 1995; revised 2 January 1996; accepted 4 January 1996. 